\title{
Did UberX Reduce Ambulance Volume?
}

Leon S. Moskatel

David J.G. Slusky

October 24, 2017

\begin{abstract}
Ambulances are a vital part of emergency medical services. However, they come in single, homogeneous, high intervention form, which is at times unnecessary, resulting in excessive costs for patients and insurers. In this paper, we ask whether UberX's entry into a city caused substitution away from traditional ambulances for low risk patients, reducing overall volume. Using a city-panel over-time and leveraging that UberX enter markets sporadically over multiple years, we find that UberX entry reduced the per capital ambulance volume by at least $7 \%$. Our result is robust to numerous specifications.
\end{abstract}

JEL Codes: I10, I18, L91

Keywords: Uber, Ambulances, Emergencies

Moskatel: Department of Medicine, Scripps Mercy Hospital, moskatel.leon@Scrippshealth.org, 310-614-5701

Slusky (corresponding author): Department of Economics, University of Kansas, david.slusky@ku.edu, 785-8641954.

Acknowledgements: The authors thank Jason Lindo, Donna Ginther, and Lucie Schmidt for their helpful comments and suggestions. They also thank Clay Mann and Mengtao Dai of the National Emergency Medical Services Information System, through the University of Utah, for their help with the ambulance data. This paper was supported in part by the Department of Economics at the University of Kansas. 


\section{Introduction}

Even as it provides a critical service in the emergency medical services (EMS) framework, modern ambulance transportation has grown ever costlier. Emergency medical transport in an ambulance can easily exceed over a thousand dollars, usually with great surprise to the patient - and with insurance often only partially covering the expense or outright refusing to pay for transport deemed not medically necessary. ${ }^{1}$ Unnecessary ambulance use is in part due to lack of other means of transportation, and that individuals would use an alternate means of transport if one existed (Billittier et al. 1996). Many have now started to seek alternate, cheaper transport to the emergency room in the form of ride-sharing services such as Uber and Lyft. ${ }^{2}$ In addition, while ambulances typically route to the closest hospital, ride-sharing services allow the patient to choose to which hospital they present, a potentially important factor as these facilities may have differing results for the same illness, with higher-cost hospitals associated with better outcomes (Doyle, et al. 2015). Cities have noticed enough residents making this shift that they have discussed how these ride-sharing services could be integrated into their EMS frameworks. ${ }^{3}$ Furthermore, the introduction of the Affordable Care Act (ACA) has slowed ambulance response times by $19 \%$ (Courtemanche et al, 2017), exacerbating the need for a partial substitute to traditional ambulances.

Uber, the first widely available ride-sharing service, initially acted as a limo-hailing service in San Francisco in 2009, before expanding into the ride-sharing industry, with UberX, in

\footnotetext{
1 “Think the E.R. Is Expensive? Look at How Much It Costs to Get There," New York Times, 12/4/2013.

2 "Why I Used Uber Instead of an Ambulance," PCMag, 7/18/2016; "For a trip to the ER, some are opting for Uber over an ambulance," StatNews, 4/5/2017.

3 “DC EMS Department Considering Uber for Transporting Some 911 Callers," NBC, 6/11/2016.
} 
2012. By May 2017, Uber reached 5 billion rides, 76 countries and over 450 cities. $^{4}$ This rapid expansion can have varying effects on communities. For example, the entry of Uber into California was associated with a reduction in the number of drunk driving fatalities (Greenwood and Wattal, 2017); driving under the influence (DUI) citations (Dills and Mulholland, 2017); and fatal accidents at the county level (Dills and Mulholland, 2017). Conversely, Uber's entry was not associated with a reduction in drunk driving fatalities in metropolitan areas (Brazil and Kirk, 2016).

Uber has also been used previously by economists to study fundamental microeconomics questions, including the value in a labor supply model of a more flexible job (Chen et al. 2017) and the granularity of consumer demand revealed by surge pricing (Cohen et al. 2016). However, to our knowledge, no other literature in either the economics or medical literature has estimated the impact of Uber market entry on ambulance volume.

\section{Data and methodology}

Since our focus is on UberX only, we will be using the terms "UberX" and "Uber" interchangeably. For the dates of Uber entry into different markets, the Uber Newsroom blog ${ }^{5}$ was scoured in its entirety for announcements of Uber launches throughout the country from its inception until October 2, 2015, the last date which would provide a full quarter for analysis with the NEMSIS database running through December 31, 2015. Additional UberX launches were then included from external publications for the same time frame. There was thus a full fourth quarter in 2015 where Uber was certain to be present in markets; as discussed below, the emergency response data was available for services provided through December 2015. Uber was

\footnotetext{
4 " 5 billion rides, 6 continents, 76 countries, and 450+ cities," Uber Newsroom, 6/29/2017.

${ }^{5}$ https://newsroom.uber.com/
} 
considered present in a region if it was present in the market for a full quarter, including entry and exits into and from the market. ${ }^{6}$ Regions, including cities and geographic areas, for which the Uber website did not show specific boundaries were excluded. At time of data collection, Uber was present in 43 states and Washington DC, excluding Alaska, Louisiana, South Dakota, Montana, Mississippi, West Virginia and Wyoming.

Maps of the regions where Uber is active were converted from Uber's website into lists of zipcodes using a mapping tool to recreate these regions. ${ }^{7}$ As the evolution of these areas is beyond the scope of this paper, ZIP codes were removed for regions where the announcements did not explicitly state the areas of coverage ${ }^{8}$. This list of zip codes was then converted to zip code tabulation areas (ZCTAs). ${ }^{9}$ Duplicate ZCTAs were removed. ZCTAs were then correlated with the 2010 census population figures. ${ }^{10}$ ZCTAs with populations less than 50 were then removed. ZCTAs were aggregated by city to produce city-level population data.

Ambulance rates were obtained from the National Emergency Medical Services Information System (NEMSIS). NEMSIS stores ambulance response volume and ambulance rates. An ambulance response volume is defined as the number of instances in which an ambulance is used for emergency transport, as submitted by the member states and sorted by zip code. An ambulance rate is defined as city ambulance volume multiplied by one thousand and

\footnotetext{
${ }^{6}$ This includes locations such as Nevada where Uber entered the market in October 2014 before withdrawing a month later. As a result, it was considered not present for the entire quarter. Uber reentered Nevada in September 2015 after a change in legislation and has been present since.

${ }^{7}$ https://www.freemaptools.com/find-zip-codes-inside-user-defined-area.htm

${ }^{8}$ For example, the announcement for the city of Los Angeles included only references to the city itself, though the current map of coverage shows boundaries more closely resembling Los Angeles County. Subsequently, separate cities in the general Los Angeles area, though now clearly included by Uber, but whose original inclusion is unclear, were excluded. This included cities such as Palmdale.

${ }^{9}$ https://www.udsmapper.org/docs/zip to zcta 2016.xlsx

10

https://factfinder.census.gov/faces/tableservices/jsf/pages/productview.xhtml?pid=DEC 10_SF1_P1\&prodType=tab le
} 
divided by city population. A data usage agreement between NEMSIS and its member states prevents the release of information that could be used to identify rates for specific regions at the state, city, or zip code level. Consequently, zip codes with Uber entry dates that produced results where the city could be identified by those entry dates were excluded. This included cities such as San Francisco and New York where Uber was introduced early, but whose same early entry would make them identifiable.

Uber entry dates by state and city with populations were submitted to NEMSIS and merged with their aggregated ambulance volume and ambulance rates. These results were then encrypted such that individual states and cities could not be identified, and returned for analysis.

Our regression follows a generalized difference-in-differences framework at the cityquarter level.

$$
y_{c t}=\beta_{0}+\beta_{1} \text { Uber }_{c t}+\boldsymbol{\beta}_{2} \mathbf{C}_{c}+\boldsymbol{\beta}_{3} \mathbf{T}_{t}+\varepsilon_{c t}
$$

$y$ is the ambulance rate for city $c$ in quarter and year $t$. Uber is a dummy for whether Uber was or was not available for that entire quarter. $\mathbf{C}$ and $\mathbf{T}$ are city and time fixed effects. Robust standard errors are clustered at the city level.

\section{Results}

Figure 1 shows the geographic boundaries and timing of Uber's entry into each city in the United States. Warmer colors represent early entry times, whereas cooler colors represent later ones. 


\section{Figure 1: Timing of Uber Entry}

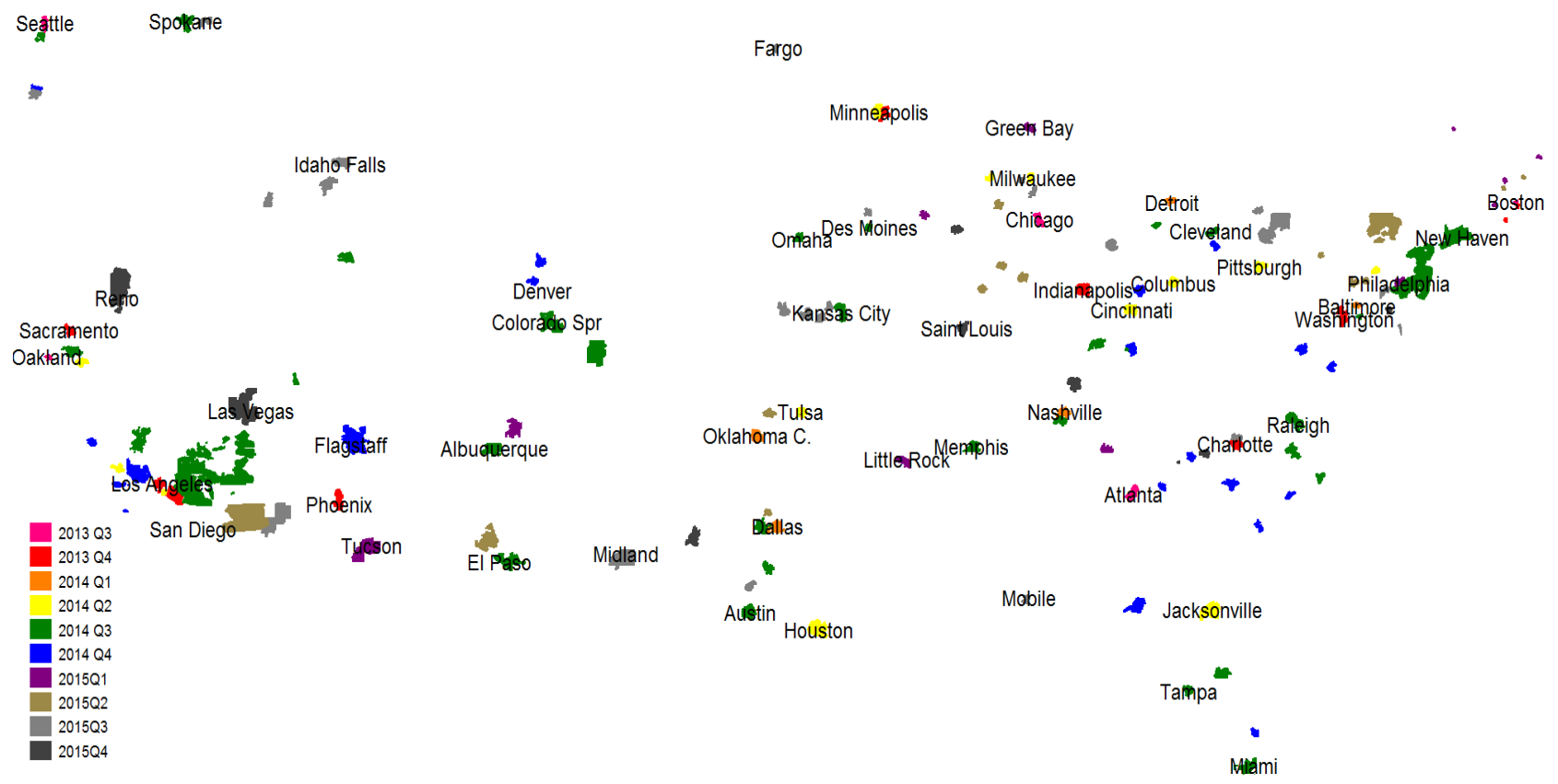

This map shows Uber spread its entry into major US cities across more than two years. It also shows that these entries were reasonably randomly distributed across the country, with no obvious pattern by region, city area, or population.

Table 1 shows summary statistics for our main variables.

Table 1: Summary statistics

\begin{tabular}{lccccc}
\hline & $(1)$ & $(2)$ & $(3)$ & $(4)$ & $(5)$ \\
& $\mathrm{N}$ & Mean & $\begin{array}{c}\text { Standard } \\
\text { Deviation }\end{array}$ & Minimum & Maximum \\
& & & & & \\
Ambulance rate & 9,272 & 16.74 & 28.86 & 0.0003 & 754.2 \\
First full quarter of Uber & 9,272 & Q3 2014 & 1.5 quarters & Q3 2013 & Q4 2015 \\
States & 43 & & & & \\
Cities & 766 & & & & \\
Cities\#States & 797 & & & & \\
& & & & & \\
\hline
\end{tabular}

We see that the mean ambulance rate is 16 ambulance response per 1000 residents per quarter, though there is a wide variation across cities. We also see that the mean Uber entrance was the 
third quarter of 2014, though some cities saw it enter as late as the end of 2015. Our data set has 766 cities, though some of those cross state lines, and so given differences in regulations and state policies, we also consider splitting those cities and consider 797 city-state groups.

Figure 2 contains shows our primary result in an event study framework. Here we define time zero as the first full quarter when Uber is available in that city (analogous to first quarter when our Uber dummy variable equals 1). The black, vertical, dashed line is therefore the last quarter before treatment.

\section{Figure 2: Event Study}

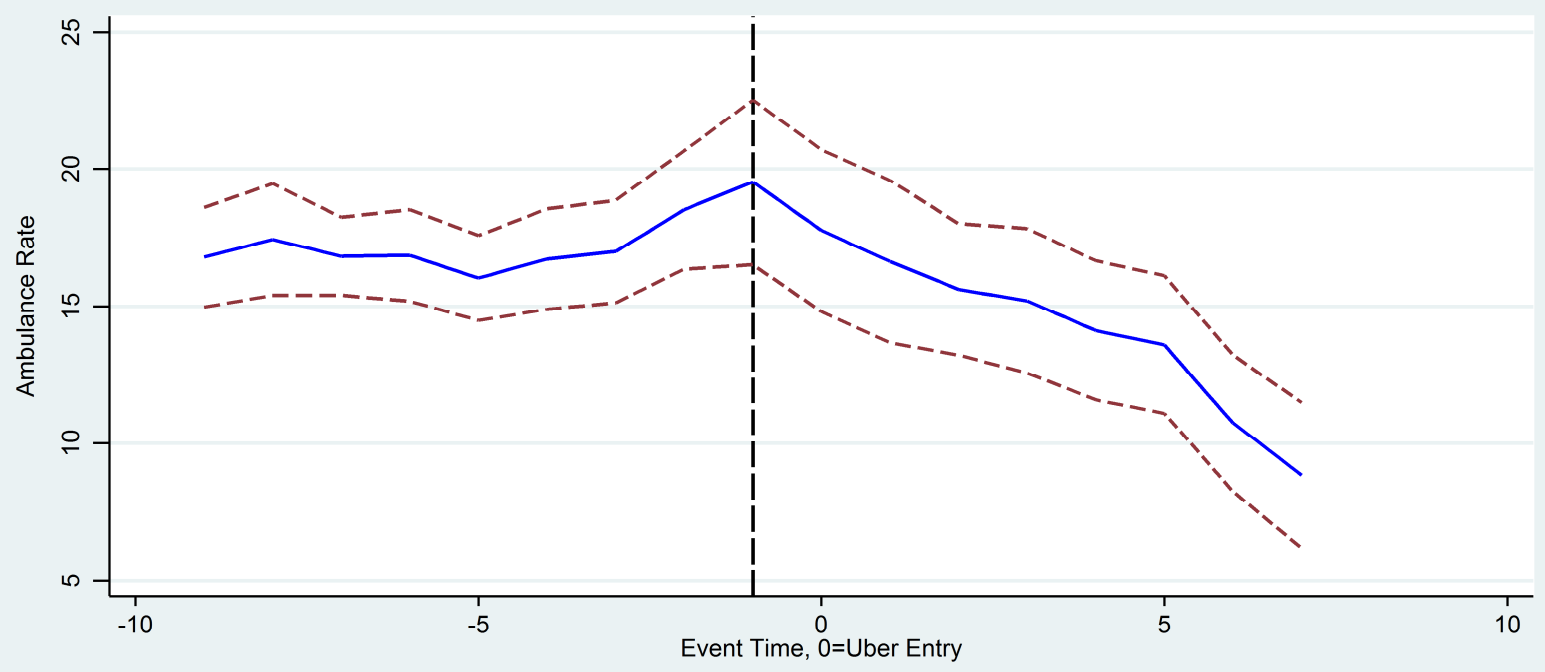

Notes: The dashed red lines show the $95 \%$ confidence interval. The vertical dashed black line shows the last quarter when Uber was not available at least some of the time.

The figure clearly shows that the ambulance rate was approximately constant in the pre-period, and then declines substantially after Uber entry. Given the small uptick in the mean ambulance rate in the two quarters before entry, below we confirm that our results are robust to dropping those two quarters of data.

Table 2 contains our main results, which are consistent across several different specifications. 
Table 2: Main results

\begin{tabular}{|c|c|c|c|c|c|c|c|c|}
\hline & $(1)$ & (2) & (3) & $(4)$ & $(5)$ & (6) & (7) & $(8)$ \\
\hline Uber available & $\begin{array}{c}-1.65^{* * *} \\
(0.485)\end{array}$ & $\begin{array}{c}-1.45^{* * *} \\
(0.419)\end{array}$ & $\begin{array}{c}-1.47 * * * \\
(0.360)\end{array}$ & $\begin{array}{l}-1.21 * * \\
(0.603)\end{array}$ & $\begin{array}{c}-1.30 * * * \\
(0.349)\end{array}$ & $\begin{array}{c}-1.64 * * * \\
(0.473)\end{array}$ & $\begin{array}{c}-1.64 * * * \\
(0.395)\end{array}$ & $\begin{array}{c}-1.68 * * * \\
(0.604)\end{array}$ \\
\hline $\begin{array}{l}\text { Fixed effects: } \\
\text { Geography } \\
\text { Quarter } \\
\text { Year } \\
\text { Quarter-Year }\end{array}$ & & $\begin{array}{l}X \\
X \\
X\end{array}$ & $\begin{array}{l}X \\
X \\
X\end{array}$ & $\begin{array}{l}X \\
X\end{array}$ & $\begin{array}{l}X \\
X \\
X\end{array}$ & $\begin{array}{l}X \\
X \\
X\end{array}$ & $\begin{array}{l}X \\
X \\
X\end{array}$ & $\begin{array}{l}X \\
X \\
X\end{array}$ \\
\hline $\begin{array}{c}\text { Time Trend } \\
\text { Quadratic } \\
\text { City-State } \\
\text { Quadratic }\end{array}$ & & & & & $X$ & $X$ & & \\
\hline $\begin{array}{l}>=14 \text { Quarters } \\
\text { Dropping } 2 \text { Q } \\
\text { Before Entry }\end{array}$ & & & & & & & $\mathrm{X}$ & $\begin{array}{l}X \\
X\end{array}$ \\
\hline $\begin{array}{l}\mathrm{N} \\
\mathrm{R}^{2} \\
\text { Unit }\end{array}$ & $\begin{array}{l}9,272 \\
0.001 \\
\text { City }\end{array}$ & $\begin{array}{c}9,272 \\
0.003 \\
\text { City }\end{array}$ & $\begin{array}{c}9,272 \\
0.003 \\
\text { City\# } \\
\text { State } \\
797\end{array}$ & $\begin{array}{c}9,272 \\
0.005 \\
\text { City\# } \\
\text { State } \\
797\end{array}$ & $\begin{array}{c}9,272 \\
0.002 \\
\text { City\# } \\
\text { State } \\
797\end{array}$ & $\begin{array}{c}9,272 \\
0.578 \\
\text { City\# } \\
\text { State } \\
797\end{array}$ & $\begin{array}{c}5,902 \\
0.034 \\
\text { City\# } \\
\text { State } \\
419\end{array}$ & $\begin{array}{c}5,064 \\
0.025 \\
\text { City\# } \\
\text { State } \\
419\end{array}$ \\
\hline $\mathrm{N}$ of units & 766 & 766 & 797 & 797 & 191 & & & 419 \\
\hline
\end{tabular}

Notes: Robust standard errors are clustered at the city level. ${ }^{* * *} \mathrm{p}<0.01,{ }^{* *} \mathrm{p}<0.05,{ }^{*} \mathrm{p}<0.1$

In column (1), we run the difference-in-differences at the city level without any controls.

Columns (2) and (3) repeat this but adding quarter (e.g., $2^{\text {nd }}$ ), year (e.g., 2015), and geography (i.e., city or city-state). The results are still statistically significant at the $1 \%$ level, albeit $12 \%$ smaller in magnitude. Column (4) adds a quarter-year (e.g., Q2 2015) fixed effect, which makes the results another $18 \%$ smaller in magnitude but still statistically significant at the $5 \%$ level. 
Columns (5) and (6) then add quadratic time trends, either common or specific to the city-state level. The results are robust to these additions. Columns (7) and (8) then begin to adjust limit the sample size, omitting cities that are missing more than two quarters of data (out of 16) and also omitting for that subset the two quarters before entry. These narrowings of the sample size do not have an appreciable effect on our results.

\section{Discussion and conclusion}

Our results represent at least a $7 \%{ }^{11}$ decrease in the ambulance rate from Uber entry into a city. This decrease likely caused a reduction in wait time for the remaining ambulance volume $^{12}$. Given that even a reduction of a few minutes can drastically improve survival rates for serious conditions (Pell et al. 2001), this could be associated with a substantial welfare improvement.

Additionally, as mentioned above ambulances are extremely expensive to patients and insurance companies. Consuming substituting to a cheaper alternative when possible would free up resources to be spent more efficiently.

Overall, our results suggest that Uber entry into a city, in addition to the more straightforward consequences found by others, has this additional positive impact on unnecessary ambulance usage.

\section{References}

Billittier et al. 1996. A Multisite Survey of Factors Contributing to Medically Unnecessary Ambulance Transports. Academic Emergency Medicine 3(11): 1046- 1052.

Brazil, N, DS Kirk. 2016. Uber and Metropolitan Traffic Fatalities in the United States J Epidemiol 184(3):192-198.

\footnotetext{
${ }^{11} 1.21 / 16.74$

${ }^{12}$ We were unable to obtain the exact response times for ambulances as they are not catalogued by a national agency.
} 
Chen, MK, JA Chevalier, PE Rossi, E Oehlsen. 2017. The Value of Flexible Work: Evidence from Uber Drivers. NBER Working Paper No. 23296.

Cohen, P, R Hahn, J Hall, S Levitt, R Metcalfe. 2016. Using Big Data to Estimate Consumer Surplus: The Case of Uber. NBER Working Paper No. 22627.

Courtemanche, C, A Friedson, AP Koller, DI Rees. 2017. The Affordable Care Act and Ambulance Response Times. NBER Working Paper No. 23722.

Dills, AK, SE Mulholland. 2017. Ride-Sharing, Fatal Crashes, and Crime Available at https://ssrn.com/abstract=2783797.

Doyle, JJ, JA Graves, J Gruber, SA Kleiner. 2015. Measuring Returns to Hospital Care: Evidence from Ambulance Referral Patterns. Journal of Political Economy 123 (1): 170214.

Greenwood, BN, S Wattal. 2017. Show Me The Way To Go Home: An Empirical Investigation Of Ride-Sharing And Alcohol Related Motor Vehicle Fatalities. MIS Quarterly 41(1): 163-187.

Pell, JP, JM Sirel, AK Marsden, I Ford, SM Cobbe. 2001. Effect of reducing ambulance response times on deaths from out of hospital cardiac arrest: cohort study. BMJ 322(7299): 13851388. 